\title{
Cell Death Mechanisms and Modulation in Traumatic Brain Injury
}

\author{
Bogdan A. Stoica and Alan I. Faden \\ Shock, Trauma and Anesthesiology Research (STAR) Center, National Study Center for Trauma and EMS, University of \\ Maryland, School of Medicine, Baltimore, Maryland 21201
}

\begin{abstract}
Summary: Cell death after traumatic brain injury (TBI) is a major cause of neurological deficits and mortality. Understanding the mechanisms of delayed post-traumatic cell loss may lead to new therapies that improve outcome. Although TBI induces changes in multiple cell types, mechanisms of neuronal cell death have been the predominant focus. Recent work has emphasized the diversity of neuronal death phenotypes, which have generally been defined by either morphological or molecular changes. This diversity has led to confusing and at times contradictory nomenclature. Here we
\end{abstract}

review the historical basis of proposed definitions of neuronal cell death, with the goal of clarifying critical research questions and implications for therapy in TBI. We believe that both morphological and molecular features must be used to clarify post-traumatic cell death and related therapeutic targets. Further, we underscore that the most effective neuroprotective strategies will need to target multiple pathways to reflect the regional and temporal changes underlying diverse neuronal cell death phenotypes. Key Words: TBI, PCD, apoptosis, neurons.

\section{INTRODUCTION}

Neuronal cell death is required for normal development of the CNS, as well as for removal of dysfunctional cells in pathological conditions including trauma. Excessive neuronal cell loss, however, underlies acute and chronic neurodegenerative disorders. ${ }^{1}$ Conceptually, trauma-induced neuronal cell loss has been characterized as either primary or secondary, with primary referring immediate cell death related to physical disruption of membranes and secondary referring to delayed cell death in surrounding or distant regions. Secondary neuronal cell death results from both physiological and biochemical changes induced by the insult.

Although cell death itself can be readily defined as the irreversible loss of integrated cellular activities or terminal disruption of key cellular substructures (or both), it has been more difficult to develop a generally acceptable taxonomy of cell death. Criteria such as type of inducer, specific molecular mechanisms, energy dependence, and morphological changes have all been used to classify cell death, leading to widespread confusion. Moreover, fail-

Address correspondence and reprint requests to: Bogdan A. Stoica, M.D., Assistant Professor, Shock, Trauma and Anesthesiology Research (STAR) Center, National Study Center for Trauma and EMS, University of Maryland, School of Medicine, Health Sciences Facility I (HSFI), 685 W. Baltimore Street, Room \#241, Baltimore, MD 21201.

E-mail: bstoica@anes.umm.edu. ure to cite critical prior work in other fields has resulted in both controversy and a tendency to oversimplify. For example, neuronal cell death has been commonly delineated into two distinct categories: necrosis, which is considered a passive process associated with loss of ionic homeostasis, failure of membrane integrity, and organelle and cell swelling, and apoptosis, often reflecting an energy-dependent process characterized by cytoplasmic and nuclear condensation and fragmentation, diminished cell volume, and relative preservation of organellar structure. The limitations of such nomenclature become readily apparent when apoptotic-type mechanisms are associated with necrotic-type morphology. ${ }^{2}$ In fact, these two patterns of cell death often coexist, and intermediate morphological forms have been identified, leading some to propose the term aponecrosis. ${ }^{3}$

\section{THE HISTORY OF CELL DEATH: MORPHOLOGICAL-BASED CLASSIFICATION}

The word necrosis, which was used by the GrecoRoman physician Galen, originates from the ancient Greek word nekros, meaning corpse. ${ }^{4}$ In the mid-19th century, Rokitansky ${ }^{5}$ and Virchow ${ }^{6}$ used the term 'necrosis' to refer to macroscopic phenomena reflecting advanced tissue breakdown. By the end of the 19th century, use of microscopy techniques revealed the connection between macroscopic necrosis and cell death. ${ }^{4}$ Various 
changes observed in the cellular nucleus after ischemia or injury were described by terms such as 'pyknosis' (chromatin condensation), 'karyolysis' (nuclear disappearance), 'karyorrhexis' (nuclear fragmentation) and 'chromatin margination' (chromatin condensation on the inside of the nuclear membrane). ${ }^{7-10}$ Cell death was also observed under physiological conditions, such as regressing ovarian follicles, with reference to pyknotic chromatin as well as cell fractionation into smaller bodies, a process called chromatolysis. ${ }^{11}$ Chromatolysis was also identified in the lactating mammary gland ${ }^{12}$ and in breast cancer tissue. ${ }^{13}$ In the early 1950s, chromatolysis was rediscovered in physiological cell death during embryo development, with the key detail that mitochondria appeared largely unaffected. ${ }^{14}$

Starting in the 1970s, Kerr, Wyllie, and colleagues in a series of seminal articles ${ }^{15-18}$ described a conserved cell death process that occurs in development, physiological tissue turnover, and various pathological conditions. This process was characterized by ultrastructural features, such as condensation of the cytoplasm and chromatin, cell shrinkage, formation of chromatin balls, normal organelles, and fragmentation of cells by budding of membrane enclosed fragments (i.e., apoptotic bodies) and the absence of an inflammatory response. Initially, they called this form of cell death "shrinkage necrosis" but later coined the term 'apoptosis,' from the ancient Greek words apo (from) and ptosis (falling), to reflect the falling leaves of autumn. Although 'apoptosis' and 'chromatolysis' were evidently different names for a similar process, Kerr, Wyllie, and colleagues were apparently not aware of the prior literature. Wyllie ${ }^{19}$ also described a "necrotic cell death" phenotype, which was present in severely injured tissues and suggested the dichotomy of apoptotic cell death and necrotic cell death.

Also in the 1970s, Schweichel and Merker ${ }^{20}$ proposed a classification of developmental cell death based on lysosomes as a key ultrastructural feature: type 1 involving lysosomes of phagocytic cells (heterophagocytosis); type 2 , involving the lysosomes of the dying cells themselves (autophagocytosis); and type 3, with no lysosomal involvement. In 1990, Clarke ${ }^{21}$ revised the Schweichel and Merker classification to include not only lysosomes but also ultrastructural changes affecting the nuclei or chromatin, cytoplasm, organelles, and cell budding or blebbing.

Each distinct cell death type shared a conserved set of ultrastructural features and was thought to reflect distinct mechanisms of cell demise. Type 1 is essentially apoptosis, wherein the apoptotic bodies are engulfed or destroyed by lysosomes of neighboring cells or macrophages. Type 2 is autophagic degeneration, marked by presence of autophagic vacuoles that destroy the cytosol and organelles of the cell. Unlike apoptosis, type 2 in general does not feature prominent nuclear pyknosis but shows dilation of organelles and is generally observed in regions undergoing massive degeneration ${ }^{20}$ (although exceptions are known in each case ${ }^{21}$ ). Most developmental cell death can be classified as type 1 or 2 in this nomenclature.

Type 3A (nonlysosomal vesiculate degradation) features prominent swelling of the organelles, presence of lacunar spaces in the cytosol and cellular disintegration without phagocytosis. Type 3B (cytoplasmic degeneration) starts with dilation of organelles and vacuolation of the cytosol, followed by nuclear degeneration by karyolysis, but the cell is phagocytosed without fragmentation. Although less common, some forms of developmental cell death reflect features of more than one type or lack a critical component. ${ }^{21}$ Type 3B developmental cell death shows ultrastructural characteristics (mitochondrial swelling, dilation of organelles, late karyolysis) similar to the necrotic cell death phenotype reported in severely injured tissues, ${ }^{19}$ further blurring the separation between physiological and pathological cell death.

Majno and Joris ${ }^{4}$ also disagree with the apoptosis versus necrosis dichotomy and argue the importance of identifying the point of no return in cell death. In their view, past this stage the cell should be considered dead, even if active processes such as cell dismantling continue. Others prefer a later threshold for death and define it as the irreversible loss of integrated cellular activity, ${ }^{22}$ which may correspond to the rupture of cell membranes and lysis of the cell, cell fragmentation in separate bodies, or cell engulfment by other cells. ${ }^{23}$ Majno and Joris ${ }^{24}$ interpret necrosis as the presence of dead tissue surrounded by living tissue. For them, necrosis is not a form of cell death, but instead reflects the secondary changes that occur after cell death, being the cellular equivalent of postmortem decay. Taking ischemia as a cell death inducer, Majno and Joris ${ }^{24}$ observe that cell swelling is one of the earliest observed changes and propose the term 'oncosis' to describe these prelethal processes leading to cell death (i.e., point of no return).

In fact, however, the term 'oncosis' (which derives from the ancient Greek word for swelling and is related to onkos, a mass or bulk) was already used much earlier to describe osteocyte cell death during rickets and during cartilage growth. ${ }^{25}$ Oncosis and type 3 cell death are virtually identical in their defining elements of cellular morphology. Majno and Joris, ${ }^{24}$ as well as others, ${ }^{26}$ propose limiting the term 'necrosis' to denote the late phases of cell degradation, irrespective of the mechanisms of the cell death. Levin et al. ${ }^{27}$ suggest adding a descriptor to mark the type of necrosis, for example apoptotic necrosis or oncotic necrosis. They argue further that only morphologic or ultrastructural analysis can inform the cell death type, and observe that other frequently used criteria are nonspecific; for example, apoptosis can affect large 
masses of cells and can be accompanied by inflamma$\operatorname{tion}^{28}$ and, alternatively, oncosis can occur in single cells.

Remarkably, few articles provide precise descriptions of cell death based on ultrastructural changes and distinguish between prelethal cell death processes (i.e., apoptosis, autophagy, or oncosis) and postlethal degradation (i.e., necrosis). In part, this may reflect the smaller number of studies using electron microcopy-based criteria, leading many authors to use the simplistic apoptosis versus necrosis dichotomy, or to focus on mechanisms rather than morphology to define cell death. Kroemer et al. ${ }^{23}$ suggest that authors refrain from making definitive pronouncements regarding cell death type and instead provide descriptive terms when presenting results (e.g., "caspase-3-positive cell death" instead of "apoptosis").

Unfortunately, this useful suggestion has largely been ignored. Thus, the term 'necrosis' is commonly used to describe both type 3-oncotic cell death and the uncontrolled cell lysis often associated with tissue inflammation. ${ }^{29}$ Nonetheless, type 1-apoptosis and type 3-oncosis can be initiated by the same triggering events, with low intensity of the insult favoring apoptosis and high intensity of the insult pushing cells toward oncosis, ${ }^{30}$ or with high intracellular ATP levels favoring initiation of apoptosis and low intracellular ATP levels associated with nonapoptotic cell death. ${ }^{31}$ Moreover, data suggest that inhibition of one cell death pathway may redirect the cell toward other mechanisms and phenotypes of cell death. ${ }^{32}$

Another key concept is that of programmed cell death (PCD) - which is not equivalent to apoptosis. Programmed cell death was first described in the 1960s, even before apoptosis, in a developmental context as cell death that occurs at a predetermined time as a result of a genetic clock. ${ }^{33}$ Others view PCD as a cell death process that follows a fixed molecular pathway. ${ }^{34}$ Because all types of developmental cell death meet one or both criteria, they can all be considered variants of PCD. A more useful definition of PCD, inspired in part by the work of Sloviter, ${ }^{35}$ suggests that PCD encompasses all active cell deaths, in which cellular processes are required for pushing the cell to and beyond the point of no return. In this interpretation, PCD requires time to develop and involves cellular mechanisms that are potentially open to therapeutic intervention. In opposition to $\mathrm{PCD}$, passive cell death results from overwhelming cell injuries (e.g., catastrophic cell damage) that instantaneously push the cell past the point of no return without involvement of active cell processes. ${ }^{36}$ Unfortunately, necrosis is often considered the paradigm of passive cell death, which incorrectly implies as untreatable many forms PCD with necrotic-type morphology, such as type-3-oncotic cell death.

\section{NEURONAL CELL DEATH IN THE CNS}

The study of neuronal cell death in the CNS is particularly challenging, because in bright-field microscopy most dying neurons appear shrunken, eosinophilic, and with pyknotic nuclei-regardless of the type of death. ${ }^{27}$ Even at the ultrastructural level, dying neurons do not well fit the cell death descriptions established in other tissues or during development. ${ }^{31}$ Thus, distinct types of neuronal cell death such as paraptosis ${ }^{37}$ have been described, featuring a requirement for gene expression, nonapoptotic morphology marked by vacuolization, and absence of caspase activation. Although it has some partial similarities with type 3B cell death (i.e., cytoplasmic degeneration), ${ }^{37}$ paraptosis is one of several forms of neuronal cell death with nonclassical morphological characteristics and with identified biochemical markers.

To attempt to clarify neuronal cell death phenotypes, studies led by Olney and Fujikawa have used ultrastructural features. In one of these studies, two types of neuronal cell death in the brain were identified, termed 'physiologic' cell death and 'excitotoxic' cell death. ${ }^{38}$ Physiologic cell death was initially characterized as a developmental death of neurons in the mammalian brain; its description is similar to type 1 -apoptosis, ${ }^{39}$ although with some features that differ from apoptosis in other tissues. ${ }^{38}$ For example, in the CNS, although organelles initially appear normal except for mild mitochondrial swelling, ${ }^{39}$ mitochondrial degeneration and endoplasmic reticulum vacuolization become prominent after rupture of the nuclear membrane. ${ }^{38}$ This pattern of orderly morphological changes is found in neurons from various brain regions during development ${ }^{38}$ or in response to diverse injuries, such as ethanol or TBI. ${ }^{40}$

In contrast, excitotoxic cell death is characterized by rapid cytoplasmic changes, including marked cell swelling, as well as dilation of mitochondria and endoplasmic reticulum, followed by their rupture. Later, chromatin condensation in the nucleus results in small chromatin clumps that eventually consolidate to form a large irregular mass at the center of the nucleus. Subsequently, the cell membrane ruptures, but the nuclear membrane remains intact. ${ }^{40}$ Excitotoxic cell death closely resembles type 3B-oncosis cell death, except that excitotoxic cell death shows more intense and longer-lasting masses of clumped chromatin.

At the ultrastructural level, excitotoxic cell death is very different from apoptosis, but these two cell death processes are more difficult to distinguish under typical light microscopy. ${ }^{39}$ Excitotoxic cell death is detected in the first hours after TBI, mostly at the local lesion site, whereas PCD is seen later, and particularly at a distance from the site. ${ }^{38}$ These authors (i.e., the Olney and Fujikawa research group) concluded that physiological cell death and excitotoxic cell death are two fundamentally 
distinct neuronal cell death types, and that the activation of one path excludes the other. Notably, this interpretation conflicts with the continuum theory, the view that these death paradigms are extremes of the same process, ${ }^{41}$ and Fujikawa et al. ${ }^{42}$ contest the existence of a cell death continuum.

Based on ultrastructural cell changes, Fujikawa et al. ${ }^{43}$ describe two unique neuronal cell death phenotypes. One has features very similar to apoptosis; the other, excitotoxic cell death, shows ultrastructural changes similar to type 3B-oncosis. Unlike non-neuronal type 3B-oncotic cell death, however, neuronal excitotoxic cell death exhibits a condensed cytoplasm and nucleus (i.e., pyknosis). Fujikawa ${ }^{44}$ also emphasizes that few if any studies demonstrate typical ultrastructural features of neuronal apoptosis outside of neonatal animals. Moreover, he concludes that widely held concepts about the apoptosisspecificity of mechanisms and markers (such as TUNEL, internucleosomal DNA cleavage, and caspase activation) have no basis, because they can be detected and are required for execution of certain excitotoxic cell death. The latter observations indicate an active cell participation (PCD) in excitotoxicity. Therefore, characterization of cell death should be based on morphology — which reflects the summation of participating factors.

\section{CELL DEATH PROGRAMS: MOLECULAR PATHWAYS THAT PARTICIPATE IN CELL DEATH}

Programmed cell death is a form of cell death executed by activation or inactivation of various molecular pathways, with multiple death phenotypes. Many varieties of PCD and associated molecular mechanisms have been identified in the CNS, as described in several excellent and comprehensive reviews. ${ }^{36,45}$ Programmed cell death has been confirmed as a major cause of posttraumatic neuronal cell death and is associated with poorer prognosis in patients after TBI. ${ }^{46}$ Morphologically defined PCD includes apoptosis, autophagy, paraptosis, calcium-dependent death, and oncosis. The cell death mechanisms that mediate the specific PCD processes include, among many others, caspases and proapoptotic members of the Bcl-2 family (apoptosis), JNK and ATG orthologs (autophagy), ERK2 (paraptosis, a cell death associated with trophotoxicity), PARP/AIF (PARP/AIF-dependent death), calpains and cathepsis (calcium-dependent death), and JNK (oncosis). ${ }^{36,45}$ Notably, few or none of these mechanisms are irreplaceably necessary for taking a cell past the point of no return. Most often, multiple mechanisms are simultaneously and redundantly activated, and in response to blocking any individual mechanism others can serve to execute the cell death. Several significant developments involving cell death mechanisms will be discussed.

\section{Cell cycle activation-dependent neuronal cell death pathways}

Mature neurons are postmitotic cells and as such were believed to be unable to re-enter the cell cycle; however, cell cycle events can be induced in mature differentiated neurons, where they lead to neuronal cell death. ${ }^{47}$ As shown in several human chronic neurodegenerative disorders, markers of cell cycle re-entry can be detected long before neuronal death, suggesting that cell cycle events may be upstream of the initiation of neuronal cell death execution. ${ }^{47}$ Acute CNS injuries such as TBI also cause activation of the cell cycle in neurons, leading to cell death. $^{47}$

Traumatic brain injury is associated with increased expression of cell cycle activation markers such as cyclin D1, CDK4, E2F5, c-myc, and PCNA, as well as downregulation of various endogenous cell cycle inhibitors, in neurons initiating molecular pathways of apoptosis such as caspase activation. ${ }^{48,49}$ Moreover, blocking cell cycle activation pathways using pharmacological inhibitors of CDKs attenuates neuronal cell death and significantly improves outcome after TBI in rodent models. ${ }^{48-50}$

\section{Caspase-dependent neuronal cell death pathways}

Caspases are cysteine aspartic acid-proteases activated by proteolytic cleavage. The cellular morphological changes that are hallmarks of apoptosis (e.g., membrane budding, chromatin condensation, and nuclear fragmentation) require caspase-dependent cleavage of specific substrates. Caspase 3 activation can occur through the extrinsic pathway involving TNF and Fas receptors, or the intrinsic pathway that involves mitochondrial outer membrane permeabilization followed by release of cytochrome $\mathrm{c}$ from mitochondria intermembrane space to the cytosol. There, cytochrome c forms an ATP-dependent complex with the apoptosis-inducing factor (Apaf-1) to activate in turn caspase 9 and caspase $3 .^{51} \mathrm{~A}$ recently proposed neuronal death concept involves dependence receptors, a group of trophic receptors that promote neuronal survival in the presence of their ligands but in the absence of their ligands can bind and activate caspases, thus becoming caspase substrates that contribute to cell death. $^{45}$

Caspase 3 appears to be the major member of the group of effector or executioner caspases, which also include caspases 6 and 7. Caspase 3 plays a major role in injury-induced neuronal loss after TBI. ${ }^{51}$ Neuronal apoptosis associated with activation of caspases has been shown after human TBI and in various animal models. $^{52-55}$ Treatment with structurally different caspase inhibitors improves outcome after experimental TBI, and prolongs the therapeutic window. ${ }^{54,56,57}$

The endoplasmic reticulum can also serve as the origin of a cell death pathway, involving caspase $12 .{ }^{58}$ Caspase 12 can be induced in the brain after TBI, suggesting that 
the endoplasmic reticulum apoptotic pathway may play a role in injury-dependent neuronal death. ${ }^{55}$

Caspase activity can be regulated by several classes of molecules. Among these, the Bcl-2 family plays an important role,. It includes Bcl-2 and Bcl-xL, which antagonize mitochondria permeabilization, as well as other proteins that have the opposite effect. This latter class includes three subtypes: one including Bax and Bak that can directly permeabilize the mitochondria; another including Bid and Bim that activate the first subtype; and one including proteins such as Bad, Puma, and Noxa that can target and inactivate Bcl-2 and Bcl-xL. ${ }^{45}$ The balance between the activities of these two antagonistic types of Bcl-2 family proteins is a major determinant of apostat (i.e., the probability of apoptotic death) and is reflected in the neuronal cell death after TBI. Increased $\mathrm{Bcl}-2$ and Bcl-xL expression in the brain after TBI is associated with attenuation of cell death and a more favorable prognosis, ${ }^{59}$ whereas increased post-TBI expression of Bax, Bad, or Bim may promote cell death. ${ }^{46}$

\section{Caspase-independent neuronal cell death pathways}

Caspase-independent mechanisms are important mediators of neuronal cell death. ${ }^{60}$ Some of the most significant findings of the last decade were that the mitochondria intermembrane space contains other proapoptotic molecules in addition to cytochrome c. After mitochondrial outer membrane permeabilization, these proteins (including Smac/DIABLO, Omi/HtrA2, AIF, and endonuclease $G$ ) may be released into the cytosol and modulate cell death. ${ }^{61-64}$

Apoptosis inducing factor (AIF) is a phylogenetically ancient flavoprotein NADH oxidase resident in the mitochondrial intermembrane space, where its oxidoreductase activities are required for oxidative phosphorylation. ${ }^{65}$ After mitochondrial outer membrane permeabilization, AIF is released into the cytosol and then translocates to the nucleus, where it binds chromatin and causes peripheral chromatin condensation and high molecular weight DNA fragmentation. ${ }^{61}$

Neuronal cell death after TBI involves AIF nuclear translocation. ${ }^{66}$ Most studies support a model in which AIF-mediated cell death is independent of cytochrome c, Apaf-1, and caspase. ${ }^{67,68}$ Some of the key regulators of AIF release from mitochondria and translocation to the nucleus include PARP-1, Cyclophilin A and HSP-70. There is experimental support for the hypothesis that AIF release is mediated by activation of PARP-1. ${ }^{69}$ Moreover, inhibition of PARP-1 activity has neuroprotective effects after TBI. ${ }^{70}$ The mechanisms proposed to explain PARP-1 dependent release of AIF from the mitochondria include depletion of cytosolic $\mathrm{NAD}^{+}$, which causes mitochondrial dysfunction and mitochondrial outer membrane permeabilization, ${ }^{71,72}$ and poly(ADP-ribose) (PAR) poly- mer, a product of PARP-1 activity having direct or calpain-mediated effects on mitochondria. ${ }^{73}$

Cyclophilins are a subgroup of peptidylprolyl cis-trans isomerases. ${ }^{74}$ Among these, cyclophilin A (cyclophilin18, СурА) appears to be both required for the translocation of AIF from the cytosol to the nucleus, as well as for the chromatolytic effects of AIF. ${ }^{75}$ CypA knockout animals demonstrate reduced infarct volume after cerebral hypoxia-ischemia, suggesting a significant role for the AIF-CypA axis in neuronal cell death in this model. ${ }^{76}$

The heat shock proteins of the HSP70 family have multiple functions, including serving as ATP-dependent chaperones and assisting the folding of newly synthesized proteins, as well as cytoprotection when upregulated in response to cellular stress. ${ }^{77}$ Increased levels of HSP70 provide neuroprotection against brain ischemia, ${ }^{78}$ whereas the absence of HSP70 results in larger lesions after ischemic injury. ${ }^{79}$ The mechanisms responsible for HSP70-dependent neuroprotection include binding of Apaf-1 and AIF, thereby neutralizing their proapoptotic function by blocking the formation of the apoptosome ${ }^{80}$ and by attenuating nuclear translocation of $\mathrm{AIF},{ }^{81}$ respectively. HSP70 overexpression attenuates ischemic brain injury by sequestering $\mathrm{AIF}^{82}$ and by reducing caspase-dependent apoptosis. ${ }^{77}$ Conversely, decreased HSP70 results in increased release of cytochrome $c$ and activation of caspase 3 with associated cell death after cerebral ischemia. $^{79}$

In contrast to caspase-mediated cell death, AIF-mediated cell death can proceed under compromised bioenergetic conditions; it is prominent in the central areas of the lesion after cerebral ischemia. ${ }^{67}$ In fact, in PARP-1dependent cell death, mitochondria release AIF as well as cytochrome $\mathrm{C}$, but caspases fail to be activated because of the associated ATP depletion. ${ }^{71,73}$ We hypothesize that, unlike the case with caspase-mediated cell death, AIF may play a larger pathophysiological role after more severe brain injuries, which are expected to result in significant bioenergetic declines.

\section{Autophagic PCD}

Autophagy is a process that involves lysosomal degradation of proteins and organelles, controlled by genes from the Atg family; under physiological conditions, it can have a protective role by generating amino acids and energy for the cell. ${ }^{45}$ Although autophagy has been often seen in dying cells, the challenge has been to determine when autophagy serves as a causal factor for cell death (autophagic PCD) and is not simply a secondary event. ${ }^{45}$ Notably, in some cell death models inhibition of the mitochondria permeabilization or activation of caspases creates conditions in which autophagy and the Atg genes are required for $\mathrm{PCD},{ }^{45}$ suggesting that autophagy might either be a process parallel but secondary to apoptosis or 
act as a compensatory mechanism initiated by inhibition of apoptosis. $^{45}$

\section{COOPERATION OF CELL DEATH PROGRAMS}

Inhibition of caspase-dependent cell death pathways may not provide substantial neuroprotection, because of the associated activation of caspase-independent PCD pathways. ${ }^{83}$ In fact, there is growing support for the hypothesis that in every stress-induced model of cell death there may be multiple pathways involved ${ }^{84}$ and that the slower or less intense mechanisms become apparent primarily when the dominant mechanisms are attenuated. $^{45}$ A key role is likely played by the cellular bioenergetic status. When this status is preserved, caspases are dominant and AIF-dependent cell death becomes important only after caspase activation has been blocked. Under bioenergetic deficient conditions, however, AIF may be the more predominant mechanism.

An important question is whether inhibition of the dominant pathway may actually initiate or enhance alternative pathways. ${ }^{3,85-88}$ Whether inhibition of the AIF pathway causes an enhanced caspase-dependent response has not been fully determined. ${ }^{89}$ There is, however, solid evidence that AIF and caspases act through parallel pathways, and that strategies that target both have potentially additive therapeutic effects. ${ }^{90}$ Autophagic and caspase-dependent PCD might also show a similar relationship. ${ }^{45}$

\section{CELL DEATH MECHANISMS: IMPLICATIONS FOR TREATMENT OF TBI}

Challenges to successful treatment of TBI-induced neuronal cell death include the presence of a multitude of cell death pathways, which have both overlapping and distinct molecular mechanisms, and the short therapeutic windows for some types of neuronal cell death. ${ }^{91}$ Furthermore, in addition to neuron-specific pathways there is also neurotoxicity secondary to microglia-initiated inflammatory responses. ${ }^{92}$ These facts might explain, in part, the failure of clinical neuroprotection trials in TBI, which too often have only targeted a single cell death pathway or have modulated mechanisms with a relatively short therapeutic window. ${ }^{91}$

In preclinical studies, improved levels of neuroprotection have been obtained using therapeutic agents with multifunctional activities, ${ }^{93,94}$ such as small cyclized dipeptides, ${ }^{95}$ progesterone, ${ }^{96}$ statins, and erythropoietin, among others. Treatment with various cyclic dipeptides significantly improved motor and cognitive recovery after TBI in both rat and mouse models, and attenuated both apoptotic and oncotic cell death in primary neurons. ${ }^{97}$ These agents limit mitochondria changes associ- ated with cytochrome c release, decrease expression of secondary injury pathways such as cell cycle proteins and cathepsins or calpains, and increase expression of neuroprotective molecules, including brain-derived neurotrophic factor (BDNF) and heat shock proteins. ${ }^{97}$

In TBI models, progesterone treatment attenuates edema and inflammatory cytokines and limits neuronal loss by preventing mitochondrial changes, with improved functional outcomes. ${ }^{96}$ Erythropoietin provides neuroprotection after experimental TBI, likely reflecting its ability to stabilize mitochondrial function and to reduce inflammation and oxidative stress. ${ }^{98,99}$ Statins have also been shown to significantly improve outcomes after experimental TBI, with effects likely due, at least in part, to their ability to activate Akt-dependent mitochondrial sparing pathways and to attenuate microglial activation. ${ }^{100,101}$ What links these therapeutic strategies is the fact that each of the compounds shows pleiotropic actions, reflecting effects on multiple secondary injury pathways that are likely synergistic. ${ }^{98}$

A different strategy is to focus on therapies that specifically, and sometimes also simultaneously, target multiple PCD mechanisms. In this paradigm, multifunctional effects can be generated by multiple drug combinations, or by targeting single factors that modulate multiple secondary injury cascades (e.g., activation of the cell cycle, ${ }^{48-50}$ PARP-1, ${ }^{70,102,103}$ calpains, ${ }^{104}$ or HSP70), among others. Targeting processes such as autophagy represents a more complex issue, in light of studies indicating both cell death and neuroprotective activity for autophagy. ${ }^{105,106}$ A schematic of several key mechanisms that mediate neuronal cell death after TBI is presented in FIG. 1, including both more mechanism-specific modulators and pluripotential agents with diverse but less clearly defined mechanisms of action.

We suggest that improved therapeutic effects may result from treatment strategies that are directed at multiple specific targets and mechanisms of cell death, using either a combination of therapeutic agents or multifunctional (i.e., pluripotential) drug strategies — or with both approaches. Optimal targets should include both caspasedependent and caspase-independent PCD. Because activation of these pathways occurs in parallel and peaks 1-3 days after injury, such strategies should be both additive or synergistic and should show a relatively wide therapeutic window. Also promising are therapies that target not only neuron-specific cell death mechanisms, but also block microglial-dependent neurotoxicity, ${ }^{92}$ or have actions on other cell types, such as oligodendroglia, ${ }^{47}$ astroglia, ${ }^{47}$ and endothelial cells. ${ }^{107}$

\section{CONCLUSIONS}

The creation of a comprehensive and rational taxonomy of cell death is difficult because of the diversity of 


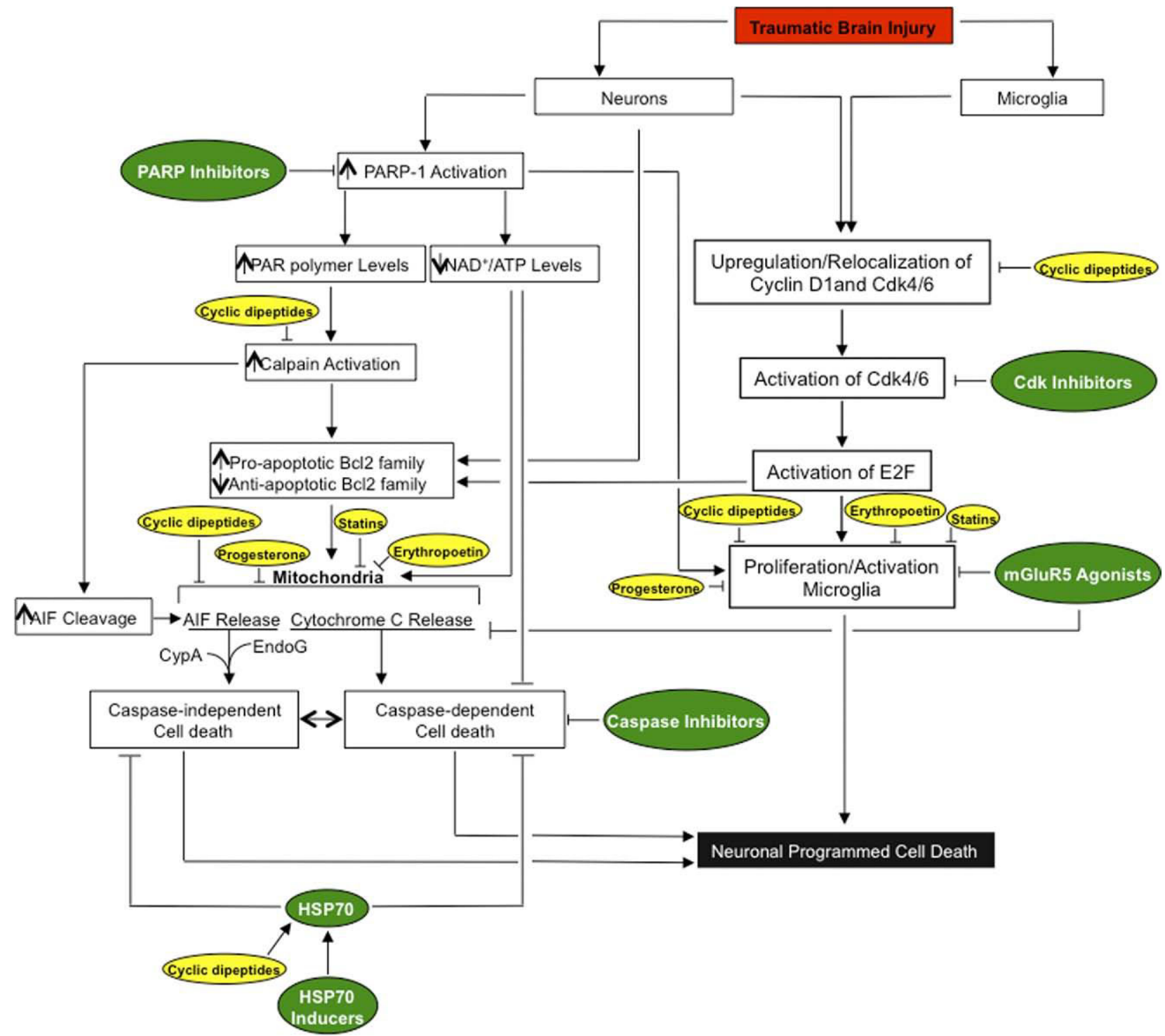

FIG. 1. Key molecular mechanisms of neuronal programmed cell death and their modulators. Green indicates more mechanismspecific modulators; yellow, pluripotential agents with diverse but less clearly defined mechanisms of action.

cell death types and the numerous molecular mechanisms involved. Moreover, a given phenotype-even with an ultrastructural requirement-may reflect different mechanisms, or the same mechanism, albeit with different expression level or intensity, may lead to different phenotypes. Nonetheless, we believe that the consistent application of several key concepts and strategies should help clarify the process.

Determination of a cell death phenotype should ideally require ultrastructural support. In the absence of ultrastructural details, a descriptive mode should be applied that includes the known morphological and mechanistic data (e.g., caspase-3-positive apoptosis). Morphology alone may be unable to address the question of programmed cell death versus passive cell death, considering that both forms of cell death share type 3-oncotic morphology. Furthermore, morphology as the final integrator of all molecular pathways involved in the cell death tends to reflect the dominant pathways and may mask the potential role of additional contributing processes. The latter issue can best be addressed by detailed mechanistic studies. It is increasingly evident that any PCD process may involve multiple, interdependent mechanisms. For these reasons, we suggest that the optimal therapeutic strategy to limit cell post-traumatic cell death is the use of combination or multipotential treatments that target multiple cell death pathways.

\section{REFERENCES}

1. Eldadah BA, Faden AI. Caspase pathways, neuronal apoptosis, and CNS injury. J Neurotrauma 2000;17:811-829. 
2. Yu SW, Andrabi SA, Wang H, et al. Apoptosis-inducing factor mediates poly(ADP-ribose) (PAR) polymer-induced cell death. Proc Natl Acad Sci U S A 2006;103:18314-18319.

3. Formigli L, Papucci L, Tani A, et al. Aponecrosis: morphological and biochemical exploration of a syncretic process of cell death sharing apoptosis and necrosis. J Cell Physiol 2000;182:41-49.

4. Majno G, Joris I. Apoptosis, oncosis, and necrosis: an overview of cell death. Am J Pathol 1995;146:3-15.

5. Rokitansky C. Handbook of general pathological anatomy [Handbuch der allgemeinen pathologischen Anatomie] [In German]. 3 vol. Vienna: Braumüller \& Seidel, 1842-1846.

6. Virchow R. Cellular pathology as based upon physiological and pathological histology [Die Cellularpathologie in ihrer Begründung auf physiologische und pathologische Gewebelehre] [In German]. Berlin: Hirschwald, 1858; English translation 1860.

7. Weigert C. An experimental and anatomical contribution to the pathology of specific types of inflammation [Ein Experimenteller und anatomischer Beitrag zur Pathologie der specifischen Entzündungsformen] [In German]. Virchows Arch Pathol Anat 1878;72:461-501.

8. Schmaus H, Albrecht E. On karyorrhexis [Über Karyorrhexis] [In German]. Virchows Arch Pathol Anat 1894;138:1-80.

9. Arnheim G. Coagulation necrosis and atrophy of the cell nucleus [Coagulationsnekrose und Kernschwund] [In German]. Virchows Arch Pathol Anat Physiol Klin Med 1890;120:367-383.

10. Klebs E. General pathology [Die Allgemeine Pathologie] [In German]. Jena: Gustav Fischer, 1889.

11. Flemming W. On the development of mammalian polar bodies within regressing Graafian follicles [Über die Bildung von Richtungsfiguren in Säugethiereiern beim Untergang Graaf'scher Follikel] [In German]. Arch Anat Entwgesch 1885;221-244.

12. Nissen F. On the behavior of the nuclei in mammary gland cells during secretion [Über das Verhalten der Kerne in den Michdrüsenzellen bei der Absonderung] [In German]. Arch Mikroskop Anat 1886;26:337-342.

13. Ströbe H. Toward understanding of various cellular phenomena in tumors [Zur Kenntnis verschiedener cellulärer Vorgänge und Erscheinungen in Geschwülsten] [In German]. Beitr Pathol Anat 1892;11:1-38.

14. Glücksmann A. Cell deaths in normal vertebrate ontogeny. Biol Rev Camb Philos Soc 1951;26:59-86.

15. Kerr JF, Wyllie AH, Currie AR. Apoptosis: a basic biological phenomenon with wide-ranging implications in tissue kinetics. Br J Cancer 1972;26:239-257.

16. Kerr JF. Shrinkage necrosis: a distinct mode of cellular death. J Pathol 1971;105:13-20.

17. Kerr JF. History of the events leading to the formulation of the apoptosis concept. Toxicology 2002;181-182:471-474.

18. Wyllie AH. Death in normal and neoplastic cells. J Clin Pathol Suppl (R Coll Pathol) 1974;7:35-42.

19. Wyllie AH. Cell death: a new classification separating apoptosis from necrosis. In: Bowen ID, Lockshin RA, editors. Cell death in biology and pathology. London; New York: Chapman \& Hall, 1981:9-34.

20. Schweichel JU, Merker HJ. The morphology of various types of cell death in prenatal tissues. Teratology 1973;7:253-266.

21. Clarke PG. Developmental cell death: morphological diversity and multiple mechanisms. Anat Embryol (Berl) 1990;181:195213.

22. Trump BF, Mergner WJ. Cell Injury. In: Zweifach BW, Grant L, McCluskey RT, editors. The inflammatory process. New York: Academic Press, 1974:115-257.

23. Kroemer G, El-Deiry WS, Golstein P, et al.; Nomenclature Committee on Cell Death. Classification of cell death: recommendations of the Nomenclature Committee on Cell Death. Cell Death Differ 2005;12 Suppl 2:1463-1467.

24. Majno G, Joris I. Commentary: on the misuse of the term "necrosis": a step in the right direction. Toxicol Pathol 1999;27:494.

25. Recklinghausen F v. Investigations of rickets and osteomalacia [Untersuchungen uber Rachitis und Osteomalacie] [In German]. Jena: Gustav Fischer, 1910.

26. Van Cruchten S, Van Den Broeck W. Morphological and bio- chemical aspects of apoptosis, oncosis and necrosis. Anat Histol Embryol 2002;31:214-223.

27. Levin S, Bucci TJ, Cohen SM, et al. The nomenclature of cell death: recommendations of an ad hoc Committee of the Society of Toxicologic Pathologists. Toxicol Pathol 1999;27:484-490.

28. Zychlinsky A, Sansonetti PJ. Apoptosis as a proinflammatory event: what can we learn from bacteria-induced cell death? Trends Microbiol 1997;5:201-204.

29. Bredesen DE. Neural apoptosis. Ann Neurol 1995;38:839-851.

30. Bonfoco E, Krainc D, Ankarcrona M, Nicotera P, Lipton SA Apoptosis and necrosis: two distinct events induced, respectively, by mild and intense insults with $N$-methyl-D-aspartate or nitric oxide/superoxide in cortical cell cultures. Proc Natl Acad Sci U S A 1995;92:7162-7166.

31. Turmaine M, Raza A, Mahal A, Mangiarini L, Bates GP, Davies SW. Nonapoptotic neurodegeneration in a transgenic mouse model of Huntington's disease. Proc Natl Acad Sci U S A 2000; 97:8093-8097.

32. Bittigau P, Sifringer M, Pohl D, et al. Apoptotic neurodegeneration following trauma is markedly enhanced in the immature brain. Ann Neurol 1999;45:724-735.

33. Lockshin RA, Williams CM. Programmed cell death. II. Endocrine potentiation of the breakdown of the intersegmental muscles of silkmoths. J Insect Physiol 1964;10:643-649.

34. Schwartz LM, Smith SW, Jones ME, Osborne BA. Do all programmed cell deaths occur via apoptosis? Proc Natl Acad Sci U S A 1993;90:980-984.

35. Sloviter RS. Apoptosis: a guide for the perplexed. Trends Pharmacol Sci 2002;23:19-24.

36. Bredesen DE. Key note lecture: toward a mechanistic taxonomy for cell death programs. Stroke 2007;38(2 Suppl):652-660.

37. Sperandio S, de Belle I, Bredesen DE. An alternative, nonapoptotic form of programmed cell death. Proc Natl Acad Sci U S A 2000;97:14376-14381.

38. Dikranian K, Ishimaru MJ, Tenkova T, et al. Apoptosis in the in vivo mammalian forebrain. Neurobiol Dis 2001;8:359-379.

39. Ishimaru MJ, Ikonomidou C, Tenkova TI, et al. Distinguishing excitotoxic from apoptotic neurodegeneration in the developing rat brain. J Comp Neurol 1999;408:461-476.

40. Bayly PV, Dikranian KT, Black EE, et al. Spatiotemporal evolution of apoptotic neurodegeneration following traumatic injury to the developing rat brain. Brain Res 2006;1107:70-81.

41. Portera-Cailliau C, Price DL, Martin LJ. Non-NMDA and NMDA receptor-mediated excitotoxic neuronal deaths in adult brain are morphologically distinct: further evidence for an apoptosis-necrosis continuum. J Comp Neurol 1997;378:88-104.

42. Fujikawa DG, Shinmei SS, Zhao S, Aviles ER Jr. Caspase-dependent programmed cell death pathways are not activated in generalized seizure-induced neuronal death. Brain Res 2007; 1135:206-218.

43. Fujikawa DG, Ke X, Trinidad RB, Shinmei SS, Wu A. Caspase-3 is not activated in seizure-induced neuronal necrosis with internucleosomal DNA cleavage. J Neurochem 2002;83:229-240.

44. Fujikawa DG. Confusion between neuronal apoptosis and activation of programmed cell death mechanisms in acute necrotic insults. Trends Neurosci 2000;23:410-411.

45. Bredesen DE. Programmed cell death mechanisms in neurological disease. Curr Nol Med 2008;8:173-186.

46. Miñambres E, Ballesteros MA, Mayorga M, et al. Cerebral apoptosis in severe traumatic brain injury patients: an in vitro, in vivo, and postmortem study. J Neurotrauma 2008;25:581-591.

47. Stoica BA, Byrnes KR, Faden AI. Cell cycle activation and CNS injury. Neurotox Res 2009;16:221-237.

48. Di Giovanni S, Movsesyan V, Ahmed F, et al. Cell cycle inhibition provides neuroprotection and reduces glial proliferation and scar formation after traumatic brain injury. Proc Natl Acad Sci U S A 2005; 102:8333-8338.

49. Cernak I, Stoica B, Byrnes KR, Di Giovanni S, Faden AI. Role of the cell cycle in the pathobiology of central nervous system trauma. Cell Cycle 2005;4:1286-1293.

50. Hilton GD, Stoica BA, Byrnes KR, Faden AI. Roscovitine reduces neuronal loss, glial activation, and neurologic deficits after brain trauma. J Cereb Blood Flow Metab 2008;28:1845-1859. 
51. Yakovlev AG, Faden AI. Caspase-dependent apoptotic pathways in CNS injury. Mol Neurobiol 2001;24:131-144.

52. Qiu J, Whalen MJ, Lowenstein P, et al. Upregulation of the Fas receptor death-inducing signaling complex after traumatic brain injury in mice and humans. J Neurosci 2002;22:3504-3511.

53. Zhang X, Alber S, Watkins SC, et al. Proteolysis consistent with activation of caspase-7 after severe traumatic brain injury in humans. J Neurotrauma 2006;23:1583-1590.

54. Yakovlev AG, Knoblach SM, Fan L, Fox GB, Goodnight R, Faden AI. Activation of CPP32-like caspases contributes to neuronal apoptosis and neurological dysfunction after traumatic brain injury. J Neurosci 1997;17:7415-7424.

55. Larner SF, Hayes RL, McKinsey DM, Pike BR, Wang KK. Increased expression and processing of caspase-12 after traumatic brain injury in rats. J Neurochem 2004;88:78-90.

56. Knoblach SM, Nikolaeva M, Huang X, et al. Multiple caspases are activated after traumatic brain injury: evidence for involvement in functional outcome. J Neurotrauma 2002;19:1155-1170.

57. Knoblach S, Fan L, Huang X, Krajewski S, Reed JC, Faden AI. Activation of caspase 3 and 9 after traumatic brain injury in the rat: treatment with a pan-caspase inhibitor improves outcome. Society Neurosci 2000;26:2300 (abstract).

58. Nakagawa T, Zhu H, Morishima N, et al. Caspase-12 mediates endoplasmic-reticulum-specific apoptosis and cytotoxicity by amyloid- $\beta$. Nature 2000;403:98-103.

59. Nathoo N, Narotam PK, Agrawal DK, et al. Influence of apoptosis on neurological outcome following traumatic cerebral contusion. J Neurosurg 2004;101:233-240.

60. Ravagnan L, Roumier T, Kroemer G. Mitochondria, the killer organelles and their weapons. J Cell Physiol 2002;192:131-137.

61. van Loo G, Saelens X, van Gurp M, MacFarlane M, Martin SJ, Vandenabeele P. The role of mitochondrial factors in apoptosis: a Russian roulette with more than one bullet. Cell Death Differ 2002;9:1031-1042.

62. Daugas E, Nochy D, Ravagnan L, et al. Apoptosis-inducing factor (AIF): a ubiquitous mitochondrial oxidoreductase involved in apoptosis. FEBS Lett 2000;476:118-123.

63. Suzuki S, Chuang LF, Doi RH, Bidlack JM, Chuang RY. Kappaopioid receptors on lymphocytes of a human lymphocytic cell line: morphine-induced up-regulation as evidenced by competitive RT-PCR and indirect immunofluorescence. Int Immunopharmacol 2001;1:1733-1742.

64. Li LY, Luo X, Wang X. Endonuclease G is an apoptotic DNase when released from mitochondria. Nature 2001;412:95-99.

65. Vahsen N, Candé C, Brière JJ, et al. AIF deficiency compromises oxidative phosphorylation. EMBO J 2004;23:4679-4689.

66. Zhang X, Chen J, Graham SH, et al. Intranuclear localization of apoptosis-inducing factor (AIF) and large scale DNA fragmentation after traumatic brain injury in rats and in neuronal cultures exposed to peroxynitrite. J Neurochem 2002;82:181-191.

67. Cregan SP, Dawson VL, Slack RS. Role of AIF in caspasedependent and caspase-independent cell death. Oncogene 2004; 23:2785-2796.

68. Candé C, Vahsen N, Garrido C, Kroemer G. Apoptosis-inducing factor (AIF): caspase-independent after all. Cell Death Differ 2004;11:591-595.

69. Hong SJ, Dawson TM, Dawson VL. Nuclear and mitochondrial conversations in cell death: PARP-1 and AIF signaling. Trends Pharmacol Sci 2004;25:259-264.

70. Whalen MJ, Clark RS, Dixon CE, et al. Reduction of cognitive and motor deficits after traumatic brain injury in mice deficient in poly(ADP-ribose) polymerase. J Cereb Blood Flow Metab 1999; 19:835-842.

71. Alano CC, Ying W, Swanson RA. Poly(ADP-ribose) polymerase1 -mediated cell death in astrocytes requires NAD + depletion and mitochondrial permeability transition. J Biol Chem 2004;279: 18895-18902.

72. Ying W, Alano CC, Garnier P, Swanson RA. NAD+ as a metabolic link between DNA damage and cell death. J Neurosci Res 2005;79:216-223.

73. Moubarak RS, Yuste VJ, Artus C, et al. Sequential activation of poly(ADP-ribose) polymerase 1, calpains, and Bax is essential in apoptosis-inducing factor-mediated programmed necrosis. Mol Cell Biol 2007;27:4844-4862.

74. Galat A. Peptidylprolyl cis/trans isomerases (immunophilins): biological diversity-targets-functions. Curr Top Med Chem 2003; 3:1315-1347.

75. Candé C, Vahsen N, Kouranti I, et al. AIF and cyclophilin A cooperate in apoptosis-associated chromatinolysis. Oncogene 2004;23:1514-1521.

76. Zhu C, Wang X, Deinum J, et al. Cyclophilin A participates in the nuclear translocation of apoptosis-inducing factor in neurons after cerebral hypoxia-ischemia. J Exp Med 2007;204:1741-1748.

77. Parcellier A, Gurbuxani S, Schmitt E, Solary E, Garrido C. Heat shock proteins, cellular chaperones that modulate mitochondrial cell death pathways. Biochem Biophys Res Commun 2003;304: 505-512.

78. Yasuda H, Shichinohe H, Kuroda S, Ishikawa T, Iwasaki Y Neuroprotective effect of a heat shock protein inducer, geranylgeranylacetone in permanent focal cerebral ischemia. Brain Res 2005;1032:176-182.

79. Lee SH, Kwon HM, Kim YJ, Lee KM, Kim M, Yoon BW. Effects of hsp70.1 gene knockout on the mitochondrial apoptotic pathway after focal cerebral ischemia. Stroke 2004;35:21952199.

80. Beere HM, Wolf BB, Cain K, et al. Heat-shock protein 70 inhibits apoptosis by preventing recruitment of procaspase- 9 to the Apaf-1 apoptosome. Nat Cell Biol 2000;2:469-475.

81. Gurbuxani S, Schmitt E, Candé C, et al. Heat shock protein 70 binding inhibits the nuclear import of apoptosis-inducing factor. Oncogene 2003;22:6669-6678.

82. Matsumori Y, et al. Hsp70 overexpression sequesters AIF and reduces neonatal hypoxic/ischemic brain injury. J Cereb Blood Flow Metab 2005;25:899-910.

83. Volbracht C, Leist M, Kolb SA, Nicotera P. Apoptosis in caspaseinhibited neurons. Mol Med 2001;7:36-48.

84. Proskuryakov SY, Konoplyannikov AG, Gabai VL. Necrosis: a specific form of programmed cell death? Exp Cell Res 2003;283: $1-16$.

85. Pohl D, Bittigau P, Ishimaru MJ, et al. $N$-methyl-D-aspartate antagonists and apoptotic cell death triggered by head trauma in developing rat brain. Proc Natl Acad Sci U S A 1999;96:25082513.

86. Chautan M, Chazal G, Cecconi F, Gruss P, Golstein P. Interdigital cell death can occur through a necrotic and caspase- independent pathway. Curr Biol 1999;9:967-970.

87. Oppenheim RW, Flavell RA, Vinsant S, Prevette D, Kuan CY, Rakic P. Programmed cell death of developing mammalian neurons after genetic deletion of caspases. J Neurosci 2001;21:47524760.

88. Yu L, Alva A, Su H, et al. Regulation of an ATG7-beclin 1 program of autophagic cell death by caspase- 8 . Science 2004 304:1500-1502.

89. Culmsee C, Zhu C, Landshamer S, et al. Apoptosis-inducing factor triggered by poly(ADP-Ribose) polymerase and bid mediates neuronal cell death after oxygen-glucose deprivation and focal cerebral ischemia. J Neurosci 2005;25:10262-10272.

90. Zhu C, Wang X, Huang Z, et al. Apoptosis-inducing factor is a major contributor to neuronal loss induced by neonatal cerebral hypoxia-ischemia. Cell Death Differ 2007;14:775-784.

91. Faden AI. Neuroprotection and traumatic brain injury: theoretical option or realistic proposition. Curr Opin Neurol 2002;15:707712 .

92. Byrnes KR, Loane DJ, Faden AI. Metabotropic glutamate receptors as targets for multipotential treatment of neurological disorders. Neurotherapeutics 2009;6:94-107.

93. Faden AI, Stoica B. Neuroprotection: challenges and opportunities. Arch Neurol 2007;64:794-800.

94. Vink R, Nimmo AJ. Multifunctional drugs for head injury. Neurotherapeutics 2009;6:28-42.

95. Stoica B, Byrnes K, Faden AI. Multifunctional drug treatment in neurotrauma. Neurotherapeutics 2009;6:14-27.

96. De Nicola AF, Labombarda F, Deniselle MC, et al. Progesterone neuroprotection in traumatic CNS injury and motoneuron degeneration. Front Neuroendocrinol 2009;30:173-187. 
97. Faden AI, Knoblach SM, Movsesyan VA, Cernak I. Novel small peptides with neuroprotective and nootropic properties. J Alzheimers Dis 2004;6(6 Suppl):S93-S97.

98. Xiong Y, Mahmood A, Chopp M. Emerging treatments for traumatic brain injury. Expert Opin Emerg Drugs 2009;14:67-84.

99. Xiong Y, Chopp M, Lee CP. Erythropoietin improves brain mitochondrial function in rats after traumatic brain injury. Neurol Res 2009;31:496-502.

100. Li B, Mahmood A, Lu D, et al. Simvastatin attenuates microglial cells and astrocyte activation and decreases interleukin- $1 \beta$ level after traumatic brain injury. Neurosurgery 2009;65:179-185; discussion 185-176.

101. Wu H, Lu D, Jiang H, et al. Increase in phosphorylation of Akt and its downstream signaling targets and suppression of apoptosis by simvastatin after traumatic brain injury. 2008;109:691-698.

102. LaPlaca MC, Zhang J, Raghupathi R, et al. Pharmacologic inhibition of poly(ADP-ribose) polymerase is neuroprotective following traumatic brain injury in rats. J Neurotrauma 2001;18:369376.
103. Clark RS, Vagni VA, Nathaniel PD, Jenkins LW, Dixon CE, Szabó C. Local administration of the poly(ADP-ribose) polymerase inhibitor INO-1001 prevents NAD + depletion and improves water maze performance after traumatic brain injury in mice. J Neurotrauma 2007;24:1399-1405.

104. Ringger NC, Tolentino PJ, McKinsey DM, Pike BR, Wang KK, Hayes RL. Effects of injury severity on regional and temporal mRNA expression levels of calpains and caspases after traumatic brain injury in rats. J Neurotrauma 2004;21:829-841.

105. Liu CL, Chen S, Dietrich D, Hu BR. Changes in autophagy after traumatic brain injury. J Cereb Blood Flow Metab 2008;28:674683.

106. Zhang YB, Li SX, Chen XP, et al. Autophagy is activated and might protect neurons from degeneration after traumatic brain injury. Neurosci Bull 2008;24:143-149.

107. Simard JM, Kent TA, Chen M, Tarasov KV, Gerzanich V. Brain oedema in focal ischaemia: molecular pathophysiology and theoretical implications. Lancet Neurol 2007;6:258-268. 